\title{
The Response to Whistleblowing by Regulators: A Practical Perspective
}

\author{
Ashley Savage and Richard Hyde ${ }^{*}$
}

Regulators need whistleblowers; whistleblowers need regulators. Modern governance relies on decentred regulatory networks, and these networks involve whistleblowers. By working together both whistleblowers and regulators add capacity and their ability to address regulatory non-compliance is enhanced. This article draws on an empirical examination of regulatory behaviour to explore how whistleblowers and regulators are working together and considers how regulators should develop their practices to ensure that the potential of whistleblowing disclosures to ensure good governance is achieved.

It is acknowledged that there is no 'universally accepted' definition of the term 'whistleblowing,' However, although the term 'whistleblowing' is not expressly defined in UK legislation, the Employment Rights Act refers to 'public interest disclosures,' which supports workers in the making of disclosures relating to risks to health and safety and the environment, miscarriages of justice, breaches of legal obligations, or a cover-up of any of the above.$^{2}$ Some argue that the act requires individuals to 'go public' ${ }^{3}$ whereas others interpret the term more widely. Near and Miceli, in the definition most often used by researchers, provide the following oft cited broad definition: "disclosure by organisation

\footnotetext{
* Senior Lecturer in Law, School of Law, Northumbria University and Lecturer in Law, University of Nottingham. Both the authors are grateful for the comments of the anonymous reviewers. This article is based on a papers delivered at the Current Issues in the Use of Information in Regulatory and Enforcement Contexts: Global Uncertainties, Ethics and Rights Conference at the University of Derby on $24^{\text {th }}$ October 2014, at a poster session at the Society of Legal Scholars Conference in Edinburgh on $3^{\text {rd }}$ and $4^{\text {th }}$ September 2014 , and at staff sessions at Northumbria University in May 2013 and December 2012.

${ }^{1}$ D. Lewis, 'What is Whistleblowing?' in D. Lewis (ed) Whistleblowing at Work (Athlone Press London) 1.

${ }^{2}$ See Employment Rights Act 1996 Part IVA. There are several possible outlets for whistleblowing communication, firstly, internal reporting to an employer, second, externally to a regulatory or other enforcement body, thirdly, to a Member of Parliament, fourthly to the media or fifthly, direct to members of the public. The primary focus of this article is on the second outlet; regulators.

${ }^{3}$ F.A. Elliston, J Keenan, P. Lockhart and J. Van Schaick (Eds), Whistleblowing Research: Methodological and Moral Issues (Praeger 1985) cited in P. Jubb, 'Whistleblowing: A Restrictive Definition and Interpretation' (1999) 21 Journal of Business Ethics 77-94, 91.
} 
members (former or current) of illegal, immoral or illegitimate practices under the control of their employers to persons or organisations who effect action." ${ }^{4}$ The Australian Senate focuses upon disclosures made to 'a person or agency capable of investigating the complaint and facilitating the correction of the wrongdoing. ${ }^{5}$ However one defines whistleblowing, we argue that such disclosures have the potential to positively influence regulatory practice.

Regulation is performed through a series of complex interactions between regulatory actors. $^{6}$ Governance cannot, and is not, simply be delivered by interactions between monolithic, all-seeing, all-knowing regulators under state control and regulated entities. Regulators do not have the ability to control risks caused by non-compliance without engaging with other actors. In her analysis of the financial services sector Black identifies at least thirteen categories of regulatory actors. ${ }^{7}$ Workers, particularly those who make whistleblowing disclosures, can have an important role as regulatory actors in the performance of regulatory functions. ${ }^{8}$ This piece argues that they can, and should, be seen by regulators as having an important function in the regulatory network as informational conduits shedding light on the compliance of their employer.

This focus contrasts with the literature on whistleblowing disclosures, which has generally focused on the person making the disclosure rather than on the disclosure itself. ${ }^{9}$ The focus on the individuals involves examining a disclosure as an exercise of freedom of expression,

\footnotetext{
${ }^{4}$ Janet Near and Marcia Miceli, Organizational dissidence: The case of whistle-blowing (1985) 4 Journal of Business Ethics 1, 4.

${ }^{5}$ Senate Select Committee on Public Interest Whistleblowing, In the Public Interest (AGPS Canberra 1994) para 2.2. Cited in Lewis, above n1.

6 Julia Black, 'The decentred regulatory state?' in Peter Vass (Ed), CRI Regulatory Review 2006/2007 (Centre for the Study of Regulated Industries, University of Bath 2007), 253.

7 Julia Black, 'Enrolling Actors in Regulatory Systems: Examples from UK Financial Services Regulation' [2003] Public Law 63, 70.

${ }^{8}$ As mentioned briefly by Black, ibid. 69.

${ }^{9}$ See generally, S.Bok, Secrets: on the Ethics of Concealment and Revelation (Vintage 1989); 210; Marcia Miceli and Janet Near, Blowing the Whistle: The Organizational \& Legal Implications for Companies and Employees (Lexington 1992); and G. Vinten, 'Whistleblowing-fact and fiction: An introductory discussion' in G. Vinten (ed.), Whistleblowing--Subversion or Corporate Citizenship? (Paul Chapman 1994).
} 
with truth, autonomy and democratic participation providing rationales for such disclosure. ${ }^{10}$ Whilst this is a valuable perspective, it provides only half the story, and the role that disclosure can play in good regulation provides an important justification for extensive whistleblower protection and an argument that the practice of regulators should support disclosure.

In part 1 , this article briefly outlines the theoretical importance of whistleblowing to regulators, emphasising the value of the information that it is possible for the regulator to obtain from workers. Parts 2 and 4 explore how regulators handle concerns disclosed to them by whistleblowers. Part 2 examines the recently reformed legislative framework governing whistleblowing disclosures, contained in the Employment Rights Act 1996 Part IVA and accompanying secondary legislation. ${ }^{11}$ Part 4 reports and analyses the results of empirical research exploring the reception and use of whistleblowing disclosure by 48 national regulators listed in the prescribed persons list, with a range of regulatory responsibility from health, finance and environment to food and health and safety, and 408 county, district and unitary entitled to receive protected disclosures regarding breaches of food law. Freedom of information requests were submitted asking for details of disclosures received, and the results of these requests are examined. The details of this methodology are briefly outlined in part 3. Part 5 draws conclusions, and makes suggestions for best practices that may support regulators in obtaining information from whistleblowers, and in ensuring that the risks disclosed by whistleblowers can be addressed. This is particularly

\footnotetext{
${ }^{10}$ See e.g. S. Bok, Secrets: on the Ethics of Concealment and Revelation (Vintage 1989); A. Mason, 'The Relationship Between Freedom of Expression and Freedom of Information' in J. Beatson and Y. Cripps (eds) Freedom of Expression and Freedom of Information: Essays in Honour of Sir David Williams (OUP 2000).

${ }^{11}$ Part IVA was inserted by the Public Interest Disclosure Act 1998, and the whistleblowing provisions of the Employment Rights Act 1996 are therefore often known as PIDA.
} 
timely given the current moves to reform both legislation and practice surrounding whistleblowers. $^{12}$

\section{1 - The Role of Whistleblowing in Regulation}

Regulator-regulated relationships are beset by information asymmetries. The regulated know much more about their behaviour than it is possible for the regulator, limited by temporal and monetary resources, to know. ${ }^{13}$ Scholars argue that the rational self-interest of the firm in not incurring costs (both directly and indirectly imposed) as a result of selfreporting prevents the disclosure of information to the regulator by the regulated entity. ${ }^{14}$ Indeed non-compliance may be (deliberately) hidden during routine inspections. ${ }^{15}$ Therefore, information about non-compliance must come from other sources.

Information gathering through investigations and from other sources is seen as central to the role of the regulator, allowing non-compliance to be identified and interventions made to ensure behaviour is modified. ${ }^{16}$ Regulators, particularly those using risk-based regulatory strategies, require information about the relative risks posed by regulated entities in order to operate. ${ }^{17}$ This information will not come from the business. It also cannot come

\footnotetext{
${ }^{12}$ Both the Whistleblowing Commission (set up by Public Concern at Work) (The Whistleblowing Commission, Report on the effectiveness of existing arrangements for workplace whistleblowing in the UK (Public Concern at Work 2013)) and the Department for Business Innovation and Skills (Department for Business Innovation and Skills, Whistleblowing Framework Call for Evidence: Government Response (DBIS 2014)) have recently consulted on reform to the handling of whistleblowing disclosures.

13 Diane Vaughan, 'Autonomy, Interdependence and Social Control: NASA and the Space Shuttle Challenger' (1990) 35 Administrative Science Quarterly 225, 228;

${ }^{14}$ Sarah L Stafford, 'Should you turn yourself in? The consequence of environmental self-policing' (2007) 26 The Journal of Policy Management and Analysis 305

15 The Mid-Staffordshire Hospitals Inquiry identified failures in both inspection processes and the way in which complaints from whistleblowers were handled: Report of the Mid-Staffordshire NHS Foundation Trust Public Inquiry, HC 89-1 (2013).

${ }^{16}$ Christopher Hood, Henry Rothstein, and Robert Baldwin, The government of Risk: Understanding risk regulation regimes (OUP 2001)

17 See Julia Black and Robert Baldwin, 'Really Responsive Risk-Based Regulation' (2010) 32(2) Law and Policy 181, 198 “risk-based regulation... is a strategy that requires a significant amount of information."
} 
completely from the regulators own investigations, as these investigations only present a snapshot of the behaviour of a regulated entity. ${ }^{18}$

One type of regulatory actor, and source of information, may be workers. ${ }^{19}$ Whistleblowing may function to enrol workers in the regulatory monitoring process. Engaging workers may be seen as particularly important when regulators are responsible for complex business organisations, which are opaque and therefore where regulators have difficulty assessing compliance (or otherwise). ${ }^{20}$ Traditionally, the enrolment of workers into regulatory networks as information sources has been underexamined, with a focus on identification of regulatory non-compliance through a disclosure by a member of the public or by detection during a routine inspection. ${ }^{21}$

Whistleblowers have a "differential regulatory capacity" than the regulatory body because they are present throughout the businesses performance of its regulatory obligations, ${ }^{22}$ providing increased information and expertise and improved strategic position when compared to the regulator. ${ }^{23}$ They may therefore be better able to detect and disclose risks. This differentiated capacity can be leveraged to present a fuller picture of the risks posed by regulated entity in order to allow steps to be taken to manage the risk. The potential

\footnotetext{
${ }^{18}$ See Phillip Beaumont, 'The Limits of Inspection: A study of the workings of the government wages inspectorate' (1979) 57 Public Administration 203.

${ }^{19}$ Julia Black, 'Enrolling Actors in Regulatory Systems,' above n7, 70 identifies "individuals within the firm, including compliance officers, executives, back office and front office staff" as potential regulatory actors.

${ }^{20}$ Indeed, the importance of whistleblowing to support regulatory practice has been globally recognised in the context of the regulation of corrupt practices, which are highly likely to be hidden (see The United Nations Convention on Corruption 2003 concerns the establishment of anti-corruption bodies which allow individuals to report corruption (Article 2). Article 33 provides protection for those who report corruption to 'competent authorities.' For commentary see Indira Carr and David Lewis, Combating corruption through employment law and whistleblower protection, (2010) 39(1) Industrial Law Journal 52-81. See also G20 Anti-Corruption Action Plan, Action Point 7 Protection of Whistleblowers, G20 Seoul 2010.)

${ }^{21}$ See e.g. Ross Cranston, Regulating Business: Law and Consumer Agencies (Macmillan Press, London, 1979); Bridget Hutter, The Reasonable Arm of the Law (Clarendon, London, 1988); Keith Hawkins, Law as Last Resort: Prosecution Decision-Making in a Regulatory Agency (OUP, Oxford, 2002).

${ }^{22}$ Black, above n6, 260. For detailed discussion of regulatory capacity see Julia Black, 'Enrolling Actors in Regulatory Systems,' above n7, 72-82.

${ }^{23}$ Julia Black, 'Enrolling Actors in Regulatory Systems,' above n7.
} 
importance of whistleblowing to regulators can be demonstrated through the use of counterfactual examples. The Public Interest Disclosure Act 1998 was drafted and enacted against the background of a number of incidents during the 1980s and 1990s including the Clapham Rail Crash, the Piper Alpha explosion, the Herald of Free Enterprise tragedy and the Maxwell Pension scandal, all of which may have been preventable had information about regulatory non-compliance have been disclosed earlier to responsible authorities (both inside and outside the organisations). More recently, the South Wales E. Coli outbreak could possibly have been averted if workers at Tudors had spoken out about their knowledge of regulatory non-compliance in the preparation of raw and cooked meat products. ${ }^{24}$ Each of these could be seen as an example of regulatory failure, resulting from the inability of enforcers to identify potentially damaging regulatory non-compliance. Whistleblowing disclosures by workers aware of the serious deficiencies that contributed to these incidents could have enabled their prevention.

Whether the capacity of the regulator is in fact enhanced by the enrolment of the whistleblower into the regulatory network depends on the institutional structure of the regulator and the way that it responds to whistleblowing disclosures. ${ }^{25}$ As the enrolment of the whistleblower into the regulatory network is a voluntary, ad hoc, process, failure to have in place appropriate practices and procedures for dealing with whistleblowing disclosures can present a barrier to the enrolment of whistleblowers. ${ }^{26}$ Failure to respond to

\footnotetext{
${ }^{24}$ Hugh Pennington, The public inquiry into the September 2005 outbreak of E coli 0157 in South Wales (Welsh Assembly Government 2009) 6.29ff.

${ }^{25}$ Black, above n6, 262.

${ }^{26}$ Etienne argues that regulators may in some cases seek to exclude individuals, such as whistleblowers, from governance networks for fear that interventions could damage existing network relationships, particularly with businesses (see Julien Etienne, 'The Politics of Detection in Business Regulation' (2014) Journal of Public Administration Research and Theory Advance Access available at $<$ doi:10.1093/jopart/muu018> 24).
} 
whistleblowing disclosures (or to share whistleblowing disclosures with bodies with the regulatory capacity to respond) and failure to protect whistleblowers from adverse consequences of whistleblowing are the major barriers to whistleblower enrolment. Whilst the legal framework, addressed in Part 2 below, attempts to reduce the second barrier, this piece draws on the empirical work carried out by the authors to argue that these barriers still exist and modifications to practice and procedure should be made to enable whistleblowers to more fully enrol in governance networks.

Whilst this article primarily argues that whistleblowers can make an important and unique contribution to regulatory practice it argues as a corollary that regulators can play an important role for whistleblowers, vindicating and addressing their concern. Indeed, it is allowing a concern to be addressed that whistleblowing has its greatest utility. As Near and Miceli identify "whistle-blowing - in and of itself - is not an unqualified good; its benefits are gained only when the complaint is valid and is effectively handled, resulting in positive change."27 Whistleblowing will only have performed its desired role when regulators are enrolled to address the concern disclosed. Regulators have the necessary regulatory capacity, particularly legal authority and organisational capacity, to allow them to modify the behaviour of regulated entities more effectively than whistleblowers themselves. This mutual dependence is a hallmark of decentred regulatory governance, with both workers and regulators needing each other to ensure that a desired outcome (regulatory compliance and reduced risk) can be achieved. ${ }^{28}$ Through a whistleblowing disclosure by a worker and a response by a regulator the regulatory capacity of both is enhanced, as the whistleblower

\footnotetext{
${ }^{27}$ Janet Near and Marcia Miceli, 'Effective Whistle-blowing' (1995) 20(3) The Academy of Management Review $679,679$.

${ }^{28}$ Black, above n6, 260.
} 
would not have had the organisational capacity to affect changes within the regulated entity and the regulator would not have been positioned to detect the regulatory non-compliance.

\section{2 - The Current Legal Position}

One method of encouraging the enrolment of whistleblowers into regulatory networks is to provide legal protection against reprisals resulting from their disclosure. In the UK, the protection of workers who make whistleblowing disclosures is currently governed by Part IVA of the Employment Rights Act 1996 ('ERA'), inserted by the Public Interested Disclosure Act 1998 ('PIDA'), and provisions of PIDA itself. The provisions are collectively referred to in this article as PIDA

\section{Public Interest Disclosure Act}

PIDA provides employment protection for individuals who raise concerns. Use of the term 'protection' is somewhat of a misnomer. The Act allows individuals to sue an employer for damages at an Employment Tribunal if they suffer detrimental treatment or dismissal. ${ }^{29}$ In order to be a protected instance of whistleblowing under PIDA, the person must make a 'qualifying disclosure.' Such a disclosure must be made in the public interest and fall within one of the categories set out in PIDA section $43 \mathrm{~B}(1)$. The categories of disclosure protected extend to information regarding: (i) a criminal offence, (ii) a failure to comply with any legal obligation, (iii) a miscarriage of justice, (iv) danger to the health and safety of any individual, (v) damage to the environment, (vi) or the deliberate concealment of information tending to

\footnotetext{
${ }^{29}$ Examples of detrimental treatment include demotion or failure to promote.
} 
show any of the matters listed above. ${ }^{30}$ Regulatory breaches are likely to be criminal offences, or failures to comply with legal obligations. Certain information of interest to regulators may fall within categories (vi), for example information disclosed to the HSE or a local authority with jurisdiction over health and safety breaches, and (v), for example information disclosed to the Environment Agency.

The Act operates a "stepped" disclosure regime. At the lowest 'step' an worker will most easily receive protection if they report concerns internally to someone in their line management chain, a nominated officer or their employer. The worker is required to show that the disclosure was made in the public interest ${ }^{31}$ and has the reasonable belief that the information raised is true. ${ }^{32} \mathrm{~A}$ worker may also raise a concern with a person designated by his or her employment contract or by a workplace policy. ${ }^{33}$ The person designated may be a regulator. Public-sector workers may raise a concern with a Minister responsible for his or her department. ${ }^{34}$

The second 'step' allows for protection if a concern is raised to a 'prescribed person.' Prescribed persons are identified in the schedule to the Public Interest Disclosure (Prescribed Persons) Order 1999 (as amended), which lists regulatory bodies, along with a description of matters in respect of which persons are competent to accept disclosures. In contrast to the internal disclosure route outlined above, the worker must make the disclosure to a person listed in the schedule to the Prescribed Persons Order (as amended); with reasonable belief that the relevant failure falls within any description of matters which

\footnotetext{
${ }^{30}$ Section 43B Part IVA ERA.

${ }^{31}$ As per section 43B Part IVA ERA.

${ }^{32}$ Section 43C Part IVA ERA.

${ }^{33}$ Section 42C Part IVA ERA. However, employers are not required to put in place a whistleblowing policy or procedure.

${ }^{34}$ Section 43E Part IVA ERA.
} 
applies to the prescribed person; and with reasonable belief that the allegations contained in the disclosure are substantially true. ${ }^{35}$ This contrasts with $\mathrm{s.43C}$ where the worker does not have to show that the allegation is substantially true but rather that he or she held the reasonable belief that it was true.

The third and final 'step' contained in S.43G allows for wider disclosures, for example to the media. It requires more stringent evidential requirements to be satisfied before the whistleblower will be afforded protection. First the disclosure must be 'qualifying' and be made in the public interest. ${ }^{36}$ The worker must believe that the information disclosed and any allegations made are substantially true and the disclosure must not be made for personal gain. In addition the worker must prove that either, at the time they made the disclosure, they reasonably believed that they would be subjected to a detriment by his employer if they raised a concern to them, and/or that no person is 'prescribed' to deal with the concern and the worker reasonably believes that it is likely that evidence relating to the relevant failure would be concealed or destroyed if they made a disclosure to their employer, or he or she has raised the concern previously to their employer or to a prescribed person. In addition to satisfying the aforementioned provisions, in all circumstances of the case it must be reasonable for the worker to make the disclosure.

In determining reasonableness, the tribunal will have regard to the identity of the person to whom the disclosure is made, the seriousness of the relevant failure and whether the relevant failure is continuing or is likely to occur in the future. The tribunal will also have regard to whether the disclosure has been made in breach of confidence, where a duty is

\footnotetext{
${ }^{35}$ Section 43F(b) Part IVA ERA.

${ }^{36}$ As per section 43B Part IVA ERA.
} 
owed either to the employer or any other person. ${ }^{37}$ Finally, the tribunal will consider whether the disclosure has been made previously to an employer or prescribed person and the action taken or action that the recipient might reasonably have been expected to take as a result. If a disclosure has been made to an employer, regard will also be given to whether the worker complied with any available whistleblowing procedure.

\section{The stepped disclosure regime}

The Public Interest Disclosure Act 1998 skilfully achieves a delicate balance between the public interest and the interests of employers. ${ }^{38}$ It aims to achieve such a balance by encouraging workers to utilise internal whistleblowing mechanisms or make disclosures to prescribed persons because they provide the most accessible evidential requirements of the three steps. The prescribed persons are, in general, regulators, and the stepped disclosure regime supports the disclosure to these bodies by making PIDA protection subject to less stringent tests.

\section{Prescribed Persons}

Providing prescribed persons allows a 'half way house' that workers can approach before making a public disclosure. ${ }^{39}$ Disclosures may be made to prescribed persons because they can handle concerns under obligations of confidence. ${ }^{40}$ PIDA does not confer automatic prescribed person status on all regulators. Instead, the Secretary of State must prescribe a

\footnotetext{
${ }^{37}$ Where a disclosure is in the public interest, this disclosure will not amount to a breach of confidence.

${ }^{38}$ The words of Lord Nolan repeated in the British Standards Institute, Whistleblowing Code of Practice (BSI 2008) 5.

${ }^{39}<$ http://www.cfoi.org.uk/pidconsult97.html\#how $>$ (last accessed $4^{\text {th }}$ January 2014) at 3.6.

40 Ibid.
} 
regulator, or body carrying out regulatory functions, by way of a statutory order. ${ }^{41} \mathrm{~A}$ regulator does not receive any extra resource when added to the prescribed persons list (as amended), and does not appear to be offered training in carrying out this role. Currently, there are 61 regulators prescribed for the purpose of receiving concerns, although when the research was conducted 48 regulators were prescribed. ${ }^{42}$ The prescribed persons list (as amended) sets out both the name of the authority and the function(s) for which the authority is prescribed. In the past bodies have been prescribed in respect of some of their functions, but not in respect of others. For example, until $6^{\text {th }}$ April 2014 the Civil Aviation Authority is prescribed in respect of aviation safety only. After that date it is prescribed in relation to both aviation safety and aviation security. ${ }^{43}$

The prescribed persons list does not impose regulatory burdens on business, or new functions on regulators. It seeks to encourage disclosures to regulators, rather than to the media. Whilst the flexible nature of PIDA affords the opportunity for workers to raise concerns, and therefore enrol in the regulatory network, without having to having to follow a rigidly prescribed disclosure regime, this flexibility has resulted in unintended consequences; namely inconsistent concern handling by individual regulators and a number of regulators with important public functions lacking prescribed status. ${ }^{44}$

There are a number of regulators who are not currently prescribed under PIDA. Regulatory Enforcement and Sanctions Act 2008 Schedule 5 lists a number of regulators, some of which

\footnotetext{
${ }^{41}$ See e.g. Public Interest Disclosure (Prescribed Persons) Order 1999 (as amended).

${ }^{42}$ The split of the Financial Services Authority into the Financial Conduct Authority and Prudential regulation Authority and the addition of a number of professional healthcare bodies by the Public Interest Disclosure (Prescribed Persons) (Amendment) Order 2013 accounts for this increase.

${ }^{43}$ See Public Interest Disclosure (Prescribed Persons) (Amendment) Order 2013/2213 article 4.

${ }^{44}$ Ashley Savage, Legislative Flexibility versus Procedural Rigidity: A Comparison of the UK and Canadian Approaches to Public Service Whistleblowing Protection, paper presented to 40th World Congress of the International Institute of Sociology, New Delhi, India (2012).
} 
have been given prescribed status by the various Prescribed Persons Orders and other which have not. The provision of prescribed status to some regulators whilst others remain un-prescribed creates a hierarchy of both regulators and public interest concerns. Those regulators who are prescribed may be considered to be more important than those who are not. The concerns that prescribed regulators may receive may be deemed more important than those received by regulators who do not have prescribed status.

There are no identifiable reasons as to why several national regulators remain un-prescribed despite a number of amendments to the prescribed persons list (as amended). The Security Industry Authority and the Gangmasters Licensing Authority, for example, carry out important regulatory functions. Similarly, Natural England and Natural Resources Wales have enforcement powers that deal with vital environmental issues. Despite harm to environment being deemed a qualifying disclosure worthy of protection under PIDA, these bodies are not prescribed. Whilst it is acknowledged that an employment tribunal must take into account the recipient of the disclosure ${ }^{45}$ the claimant would still need to satisfy more stringent evidential criteria than those raising concerns to prescribed regulators and is therefore placed in a strategically worse position than an individual who raises concerns to a prescribed regulator, inhibiting whistleblowers from enrolling into the regulatory network.

Workers may encounter difficulty in identifying, first, whether the regulator they want to raise their concern to is prescribed or not and, second, whether the prescribed regulator investigates the type of concern they want to raise. The Public Interest Disclosure (Prescribed Persons) Order 1999 is often unclear regarding the scope of prescription, unless

\footnotetext{
${ }^{45}$ Section 43G(3)(a) ERA 1996.
} 
the whistleblower is also aware of the statutory functions of the regulator. In particular, whistleblowers are unlikely to be aware of the division of responsibility for health and safety between the HSE and local authorities, or between county and district level local authorities. Where the worker raises a concern with the wrong regulator there is a risk that they will not obtain protection under the Act. ${ }^{46}$ If this risk arises the future enrolment of whistleblowers into regulatory networks may be impeded.

Even where a regulator has been afforded prescribed status, the handling of whistleblowing concerns varies from regulator to regulator. The lack of a consistent approach means that a worker who discloses to one regulator may have a better result in getting the wrongdoing addressed than a person who discloses the concern to another.

The authors undertook what is believed to be the first comprehensive empirical investigation into the use of whistleblowing disclosures by regulators. ${ }^{47}$ Two studies were undertaken. In the first, the authors used Freedom of Information requests to obtain information about handling of whistleblowing disclosures from the 48 national prescribed persons listed in the schedule to the Public Interest Disclosure (Prescribed Persons) Order 1999 (as amended). In the second, Freedom of Information requests were sent to 408 local authorities to ask about their handling of whistleblowing disclosures concerning breaches of food law. A discrete regulatory area was chosen as the basis of the request to the local authorities because when the authors asked about the receipt of whistleblowing disclosure generally authorities tended to indicate that a response would exceed the cost limit

\footnotetext{
${ }^{46}$ See Dudin v Salisbury District Council (ET, Case Number 3102263/03, 20 ${ }^{\text {th }}$ February 2004).

${ }^{47}$ Although David Lewis, 'A survey of whistleblowing/confidential reporting procedures used by persons prescribed under the Public Interest Disclosure Act 1998' [2007] Communications Law 125 examined the procedures put in place by prescribed persons, his study did not focus on the role played by these disclosures in regulation.
} 
prescribed by the Freedom of Information Act, and would therefore not be provided. Local authorities are prescribed persons for this purpose, so any disclosure received would be a second step disclosure. The authors have published a more detailed examination of the methodology, which can be consulted if further details are required. ${ }^{48}$ Over half the national regulators $(n=25)$ and around half the local authorities responded by providing data, which is analysed below. Some larger regulators, including the Financial Services Authority and the HSE, refused to respond as providing the information would exceed the prescribed cost limit. In part 4 below the empirical reality of the handling of whistleblowing disclosures is considered, leading to the suggestions for reform advanced in the final section.

Our request asked regulators to identify the number of disclosures from whistleblowers that were received in the period between 2005 and 2010, and to give information about the handling of these disclosures. Regulators were also asked whether information was shared with other regulators, particularly where the disclosure fell outside their competence. Such information sharing is particularly important in ensuring that data reaches the body able to effectively respond to the regulatory non-compliance.

\section{4 - Practical perspectives on the role of whistleblowing disclosures on regulatory practice}

The data received in response to the freedom of information requests is considered in three phases; behaviour of a regulator before a disclosure is received; during receipt of a disclosure; and after receipt of a disclosure. In order to draw conclusions on the first of these, the authors examined a number of websites of the national and local regulators to

\footnotetext{
${ }^{48}$ See Ashley Savage and Richard Hyde, 'Using Freedom of Information Requests to Facilitate Research,' (2014) 17(3) International Journal of Social Research Methodology 303 and Ashley Savage and Richard Hyde, 'Local Authority Handling of Freedom of Information Requests: Lessons from a Research Project' (2013) 19(2) Web Journal of Current Legal Issues.
} 
determine whether information about making a disclosure was simple for potential whistleblowers to access.

\section{Information available prior to whistleblowing}

In many cases it is not easy to find information about how one should make a whistleblowing disclosure. Most local authority websites do not contain specific information, and indeed often the only reference to whistleblowing is the internal policy applicable to staff, ${ }^{49}$ or a policy that only applies to particular functions of the authority. ${ }^{50}$ Many websites do not contain clear and simple instructions on the making of a disclosure. The national regulators tend to be better, but it is still the case that instructions regarding whistleblowing are not directly linked from the regulators front page, often requiring a search, or a detailed exploration of the enforcement pages, to find. This may function to inhibit the enrolment of whistleblowers who may have limited time to discover how to contact a regulator, and they may choose to either say nothing or to make a disclosure to a body without the regulatory competence to address the concern.

Potential whistleblowers should be informed of the ways that a disclosure can be made and of the subject matter over which the regulator has jurisdiction. In particular, where the regulatory landscape is complex and fractured the website should provide information that helps the whistleblower identify the correct recipient for his or her disclosure. With the two-

\footnotetext{
49 See e.g. this search of Newark and Sherwood District Council's website <http://www.newarksherwooddc.gov.uk/search/search/C.view=nsdc/results?q=whistleblowing \&s=\&sa=0\&hf=10> (last accessed $7^{\text {th }}$ January 2014$)$ which shows a number of employee policies which relate to whistleblowing, but no information that is aimed at an external person seeking to make disclosure to the Council as a regulator.

50 See $\quad$ e.g. this search of Nottingham Council's <http://gossweb.nottinghamcity.gov.uk/googlesearch/results.htm?q=whistle\%20blowing\%20procedure\#gsc.tat=0\&gsc.q=whistleblowing \&gsc.sort=> (last accessed $7^{\text {th }}$ January 2014) which shows whistleblowing mentioned in the context of safeguarding, but no policy regarding whistleblowing to the council in its regulatory function.
} 
tier local authorities examined there was little clarity regarding the distinction between authorities concerned with food hygiene matters (dealt with by environmental health officers within district level authorities) and those concerned with food standards (dealt with by Trading Standards Officers within county level authorities). The National Audit Office, with a link to information for whistleblowers on its front page, ${ }^{51}$ and detailed information about jurisdiction and contact methods, ${ }^{52}$ is a good example of how regulators should provide information to potential sources of disclosure. Perhaps it is because of this that the NAO received a high number of whistleblowing disclosures compared to other regulators in the sample who provide less clear information.

If potential whistleblowers are unable to access information quickly and easily they may be discouraged from making a disclosure. Whistleblowers may have limited time to research the pathways through which they can speak out, and if the information is not readily available may decide not to make the disclosure. Even if they do speak, there is a risk that they make the disclosure to the wrong regulator or the incorrect person within the right regulator, leading at best to a delay in addressing the risk identified by the concern, and at worst a failure to address the concern, and perhaps a failure to properly protect the whistleblower.

Even where regulators provide information, in some cases it is not up to date, with the 2013 changes to PIDA not taken into account. ${ }^{53}$ The potential whistleblower is therefore informed

\footnotetext{
${ }^{51}<$ http://www.nao.org.uk/> (last accessed $7^{\text {th }}$ January 2014).

$52<$ http://www.nao.org.uk/contact-us/contact-us/whistleblowing-disclosures/> (last accessed $7^{\text {th }}$ January 2014).

${ }^{53}$ See e.g. <http://food.gov.uk/enforcement/regulation/whistleblowing > (last accessed $7^{\text {th }}$ January 2014).
} 
of the need for good faith even though this requirement is only relevant to remedy, whilst not being informed of the public interest requirement recently inserted into section 43B.

Information provided to whistleblowers should include a phone hotline. Where risks may be particularly urgent there should be a method for a whistleblower to urgently contact the regulator. In some cases an online form was provided, but this may not function to capture the information necessary for the regulator to address the risk identified by the disclosure, and therefore the regulator may not be able to properly deal with the risk. If no (or fake) contact details are left the regulator will not be able to revert to the person making the disclosure in order to clarify. With a disclosure made by telephone, the call handler will be able to ask supplemental questions to tease out the information necessary.

\section{The conception of whistleblowing disclosures adopted by regulators}

Most regulators treated conceptualised disclosures in the terms adopted by PIDA. For example, the Scottish Commissioner for Children and Young People includes the definition of 'qualifying disclosure' in the Enquiries Service Handbook, and provides that disclosures falling within this definition are to be treated as whistleblowing disclosures. Similarly, the Food Standards Agency adopts qualifying disclosure as its definition of whistleblowing both in the publically available whistleblowing policy, and in the guidance given to staff on handling disclosures.

A number of regulators appeared to have wider definitions of whistleblowing. Whilst the Act links whistleblowing to the employment relationship, the Tenant Services Authority treated disclosures made by ex-employees (5 disclosures), tenants (16 disclosures) and even members of the public ( 5 disclosures) as examples of whistleblowing. In total, 44 disclosures 
out of 90 would not be protected under PIDA. Similarly the Pensions Regulator categorises statutory reports from professionals with an obligation to disclose under Pensions Act 2004 section 70(2) as whistleblowing disclosures.

Other regulators treat disclosures as equivalent to complaints by members of the public, and don't distinguish between whistleblowing disclosures and other types of consumer contact. In particular, local authorities adopted the view that whistleblowing disclosures and complaints from members of the public should be treated equivalently. One Welsh unitary local authority stated that "all complaints are recorded by the Council as 'Service Requests' and these can be from workers, members of public and so forth. Our system does not differentiate between them." Information received from other local authorities in response to the FOIA requests showed that this was not isolated, including large spreadsheets of complaints where the majority had clearly come from consumers but which appeared to also contain disclosures made by workers. Amongst the national regulators, an example is the Office of Rail Regulation. Similarly, a number of regulators who refused to respond to the request, such as the Environment Agency, identified the lack of separation between public complaints and whistleblowing disclosures as the reason that information about disclosures could not be provided within the costs limit in the Freedom of Information Act.

This similar treatment for the two types of information can have two types of detrimental effect. First, during the investigative phase treating disclosures as public complaints is not consistent with best practice, as steps may need to be taken following a whistleblowing disclosure to protect the identity of a source, which would not need to be taken following 
the receipt of a public complaint. ${ }^{54}$ For example, an inspection sparked by the disclosure should not focus entirely on the subject of the disclosure, as this may alert the regulated body to the identity of the whistleblower. Where the same procedures are adopted for public complaints and whistleblowing disclosures, the risk of difficulties of this type is exacerbated. If potential future whistleblowers do not trust the regulator to protect them from detriment because of the experience of previous whistleblowers then they may be dissuaded from providing information to these regulators, preventing the tackling of regulatory non-compliance. ${ }^{55}$

Second, where a regulator seeks management information to analyse the treatment of whistleblowers, this exercise will be hampered where whistleblowers are not properly identified and categorised in the data recording systems of the regulator. This may mean that weaknesses in practices and procedures which dissuade workers from coming forward cannot be identified and addressed, leading to an information detriment.

\section{Do regulators receive whistleblowing disclosures?}

The data obtained shows that direct whistleblowing disclosures were received by the majority of responding regulators during the period surveyed. Sixteen regulators reported receiving disclosures (64\%). ${ }^{56}$ The number of disclosures reported ranged from 2 reported by the Scottish Information Commissioner to 3157 reported by the Pensions Regulator. Disclosures played a regular role in some regulators practice, with Ofgem reporting

\footnotetext{
${ }^{54}$ Although, of course, public complainants may suffer detriment following a complaint, and local authorities must take action to prevent this happening in order to enrol the public into regulatory networks. However, such detriment is unlikely to be employment detriment so falls outside the protection afforded by PIDA.

${ }^{55}$ Miceli and Near, above n4, 75.

${ }^{56} 9$ regulators reported receiving no disclosures between 2005 and 2010 (Ofcom; the Care Council for Wales; the Office of Fair Trading; HM Treasury; the Water Industry Commissioner for Scotland; the Scottish Ministers; the Certification Officer; the Children's Commissioner; and the Standards Commissioner for Scotland).
} 
receiving two or three disclosures per month. For other regulators, whistleblowing disclosures were a more irregular occurrence, with the Accounts Commission for Scotland, the Children's Commissioner for Wales and the Scottish Commissioner for Children and Young People averaging less than two disclosures received per year over the period.

The data shows an increase in whistleblowing disclosures over the period 2005 and 2010. The Food Standards Agency received only three disclosures in 2007 (the first year that data was separately recorded), but by 2010 received 19 disclosures, and in 2011 received 52 . The Civil Aviation Authority received 11 disclosures in 2007 and 96 in $2011 .{ }^{57}$ Ofwat received 5 disclosures in 2007 and 13 in 2009. This may reflect an increased focus on disclosures by regulators. It may suggest improved awareness of whistleblowing amongst workers and greater trust in regulators as the recipients of whistleblowing disclosures.

Regulators operating in some spheres tend to receive a greater number of disclosures. Whilst the Office of Fair Trading, with a focus on consumer and competition law, received zero whistleblowing disclosures between 2005 and 2010, ${ }^{58}$ the Pensions Regulator received 3157 disclosures. Whilst there are some challenges in the data, with the Pensions Regulator perhaps adopting a wider definition of whistleblowing than other regulators, the large number of reports may suggest a professional culture which encourages whistleblowing and a regulator that supports such a culture.

\footnotetext{
${ }^{57}$ According to the response from the CAA, industrial action, which "tends to prompt a flurry of reports," may explain some of the rise in reports.

${ }^{58}$ Whilst Trading Standards Departments cover similar ground, and therefore could have received disclosures about non-compliance with consumer law, it is surprising that no disclosures were directed to the OFT. The nil return may therefore be an artefact of a restrictive definition of whistleblowing, combined with a greater focus on rewarded, rather than unrewarded, disclosure.
} 
Similarly, the Civil Aviation Authority received 263 disclosures in the period examined. The CAA operates in an environment where public safety and terrorism concerns are ever present. The willingness of whistleblowers to come forward is likely to be increased by the potentially dire consequences of a regulatory breach. Awareness of these potential consequences by whistleblowers is likely to drive disclosure, particularly where the employer does not take action to address concerns.

Amongst the local authorities that responded with usable data, which either disaggregated whistleblowing disclosures or allowed the authors to separate such disclosures from consumer complaints, the authorities received on average just over 1 disclosure per year. Unsurprisingly, those authorities that had more than food premises within their geographical area tended to receive more disclosures. However, authorities in general failed to receive many disclosures regarding breaches of food law.

It is suggested that this could mean one (or more) of five things; the first is that very few food safety concerns are occurring. However, this would contradict the trends within data gathered from the Food Standards Agency, where disclosures have increased from under 5 to just over 50 in the years 2007-2011, and in the Food Standards Agency report which analyses incidents reported to the FSA, which shows 7037 incidents between 2007 and $2011 ;{ }^{59}$ second, internal organisational whistleblowing procedures are effective, meaning there is no need to go to a regulator; third, that workers are reluctant to make disclosures to local authorities. This chimes with recent work undertaken by Public Concern at Work, which suggests that individuals are likely to disclose their concern to an employer and to

\footnotetext{
${ }^{59}$ Food Standards Agency, Annual report of Incidents 2012 (FSA 2012) 26.
} 
take a concern no further if no action is taken in response ${ }^{60}$ fourth, that workers are making disclosures to the wrong regulator, and particularly to the Food Standards Agency, where around $80 \%$ of the disclosures received in the period $2007-2011$ were within the jurisdiction of a local authority rather than the Food Standards Agency; or fifth, that local authorities are failing to accurately record whistleblowing concerns, as demonstrated above. It is likely to be a combination of the above factors, with a mixture of under-recording and underreporting leading to an informational deficit for local authority regulators seeking to address food safety risks. Suggestions to remedy this deficit are made in part 4.

Disclosures, therefore, clearly play a role in the in the practice of regulators, providing information on which regulatory action may be based. However, disclosures are more important for some regulators compared to others, and this may suggest different attitudes to disclosures by regulators and potential whistleblowers dependant on which regulated sector that they work in. Some regulators receive information from whistleblowing disclosures, whereas others do not. It may be that regulators in sectors where whistleblowing is rare need to take action to encourage workers to disclose non-compliance with regulatory requirements.

\section{In what form are these disclosures received?}

The act of whistleblowing communication may be carried out in three ways; openly, by an individual raising concerns and potentially making him or herself available in subsequent investigatory processes; confidentially, whereby the recipient is aware of the individual and aims to protect their identity; or anonymously, where the recipient may not be provided

\footnotetext{
${ }^{60}$ See Public Concern at Work, Whistleblowing - the Inside Story (PCAW 2013).
} 
with the opportunity to test the veracity of the claims or the motivations behind the disclosure. Some whistleblowers who make disclosures may prefer to do so anonymously, in order to protect their identity from regulated bodies. Anonymity is not perfect, ${ }^{61}$ circumstantial matters, such as the content of the disclosure, may serve to identify the whistleblower. $^{62}$

For regulators, non-anonymous communications are preferred, as anonymous communications, particularly those made in a non-interactive manner such as by letter, will often contain insufficient information on which to base regulatory action, and regulators will be unable to probe the allegation in order to obtain the necessary facts. ${ }^{63}$ In such cases regulators will not be able to follow up the disclosure to obtain more information, meaning that the whistleblower who has self-enrolled in the regulatory network has failed to enhance the regulators capacity through the provision of information. In a number of anonymous disclosures received by regulators, no further action was taken as a result of the paucity of information contained in the initial disclosure. However, this should not be the default position. Even where there is a small amount of information supplied, regulators should be alert to the possibility of non-compliance in the regulated body (even if the extent and scope of the non-compliance is not obvious), which could be assessed by a further investigative action by the regulator. Further, the information should be available to be analysed in combination with other data held by the regulator, in order to provide a broad

\footnotetext{
${ }^{61}$ It will be difficult for a worker to argue that they have suffered a detriment or dismissal for making a disclosure to a prescribed regulator or other individual under the terms of the Public Interest Disclosure Act 1998 where contact between the communicator and recipient cannot be proven. It is recognised that there are practical risks associated with workers raising concerns on a confidential basis. It may be impossible to protect the identity of an individual working in a small organisation or where they one of only a few privy to the substance of the concern raised. Subsequent investigation and enforcement action may eventually identify the source and the recipient may have a statutory obligation to report a criminal offence.

${ }^{62} \mathrm{R}$ Calland and G Dehn, Whistleblowing Around the World: Law, Culture and Practice (ODAC, Cape Town, 2004$) 8$.

${ }^{63}$ S Rains and C Scott, 'To Identify or Not to Identify: A Theoretical Model of Receiver Responses to Anonymous Communication' (2007)

17(1) Communication Theory 61, 74. For the practical difficulties associated with anonymous disclosures see Calland and Dehn, Ibid., 8.
} 
and triangulated overview of business behaviour. Therefore, anonymous information should not be ignored, but should be recorded and utilised where necessary.

Most of the regulators examined received disclosures on both anonymous and confidential bases. In the majority of disclosures regulators were aware of the identity of the whistleblower. In most cases where the whistleblower was identified these details were kept confidential. However, a significant proportion of disclosures were made on a selfidentified, non-confidential, basis. For example, nine of the 21 disclosures made to the Auditor-General for Wales were made on a non-confidential basis. Similarly, 11 of the 32 disclosures made to Monitor were made on a non-confidential basis. Other regulators, such as the CAA and Ofwat, treat all individuals who identify themselves as giving the details on a confidential basis.

In contrast to the majority of regulators, the National Audit Office showed a greater number of anonymous disclosures than confidential disclosures. Over the period studies, the NAO received 95 anonymous disclosures, compared to 36 disclosures made on a confidential basis. However, over the study period it shows a rising proportion of disclosures made on a confidential basis, accompanied by a drop in the proportion of anonymous disclosures. In 200593 percent of disclosures were made on anonymous basis, whereas in $201055 \%$ of whistleblowers identified themselves. This is a positive trend, which should increase the utility of the information provided to the NAO.

Within local authorities the trends were similar. Most authorities received a mixture of anonymous and confidential disclosures, with slightly more confidential disclosures. A number of authorities expressed a strong preference for confidential disclosures, with one going as far as to adopt a policy excluding anonymous disclosures from consideration due to 
possible unreliability. ${ }^{64}$ This seems a rather extreme position to adopt, with this policy operating to deny the regulator access to what could amount to valuable information before an investigation has been carried out to determine its provenance. Whilst the information may be unreliable and valueless, it may also provide important data and be disclosed anonymously due to legitimate fears on the part of the worker. By adopting this blanket position it is impossible to know whether the information is valuable or otherwise.

\section{What are the subjects of these disclosures?}

The disclosures received tend to relate to a wide range of subjects, some which fall within the core competence of the regulator, and some which do not. When such disclosures outside of competence are made, regulators are not able to lawfully act upon them.

The NAO received 64 disclosures relating to subjects outside the scope of their remit, compared to 72 disclosures which dealt with subjects within the scope of their regulatory function. Disclosures outside of the subject matter of the regulatory function touched on matters such as health and safety, benefit fraud and tax evasion by individuals. ${ }^{65}$

Whistleblowers should not necessarily be expected to make disclosures the correct body. The regulatory landscape, particularly in pervasive fields such as health and safety and environment, is fractured, with different regulators (both local and national) having responsibility for different businesses. For example, in health and safety regulation, the HSE are responsible for high-risk businesses, whereas local authorities deal with lower risk businesses. Within the local authority regulation of food, different authorities, and different

\footnotetext{
${ }^{64}$ Noting that they do not deal with such disclosures because they "appear to be (i.e. Anon) from ex members of staff, we do not keep a separate record of them or record them as disclosures. In general they are from staff with a grudge."

${ }^{65}$ Similarly, both Monitor and the Tenant Services Authority ('TSA') received disclosures relating to employment disputes.
} 
departments within unitary authorities, are responsible for risks resulting from breaches of food hygiene requirement and risks due to breaches of food labelling requirements. Overlaid on this fractured local landscape is the Food Standards Agency with concurrent enforcement jurisdiction over slaughterhouses, game-handling establishments and cutting plants, ${ }^{66}$ and no enforcement jurisdiction in other cases.

Disclosures made to local authorities concerned a wide range of matters. The majority focused on food hygiene, food standards and food safety matters, but other concerns, such as those relating to employment, were also received. In some cases the disclosure related to a food business situated within the area of another authority.

In other cases, regulators will be responsible for different aspects of the same regulated body. An example of this is the regulation of the NHS, where the Care Quality Commission and the Monitor have close involvement. The CQC considers the quality of care and Monitor examines financial performance. However, these areas of regulation may overlap, meaning that disclosures to one body trigger consideration by the other. In these circumstances, a disclosure to the incorrect regulator should not prevent the examination of the concern. If the concern is not examined due to disclosure being made to the wrong body, the disclosure will not have the desired effect. Therefore, it is necessary to have in place a process for redirecting the concern to the correct regulator within a regulatory network.

\section{What is the result of whistleblowing disclosures received?}

\footnotetext{
${ }^{66}$ Defined in Food Hygiene (England) Regulations 2006 regulation 5(6).
} 
When a disclosure is received within the remit of the regulator, this leads to engagement with the regulated body by the regulator. Most regulators use the tools at their disposal to seek to substantiate the disclosure made through an investigative process. Such investigations should be broad in order to protect the identity of the whistleblower. Where a post-disclosure investigation is narrowly tailored to the subject of the disclosure it may be possible for the business to identify the worker who made the disclosure, leading to subsequent detriment for that worker. This could discourage whistleblowers from coming forward in future. Therefore, disguising the investigation as part of a broader investigative programme may be necessary to ensure that the employer is not alerted to the source of the information.

In many cases following investigation it was decided that no further action was necessary. In a minority of cases the disclosure led to enhanced monitoring of the business, but in very few cases was formal enforcement action taken. Two examples of formal action can be usefully cited. Formal action was taken by Ofwat following a disclosure that complaints and sewer flooding incidents were not being correctly classified and pollution incidents were not being reported. A disclosure to the CAA led to a criminal case being mounted in Ireland.

The response of local authority's tended to mirror the response of national regulators. One local authority stated "All food disclosures were investigated and dealt with informally." This reflects the approach in most local authority cases, although in a handful of cases formal action was taken, including improvement notices and emergency prohibition orders. 
The trend of informal rather than formal action fits with the compliance stance operated by regulators, who seek to bring the regulated entity into compliance rather than to take formal action. ${ }^{67}$ By removing the barriers to compliance and explaining how compliance can be achieved, the risks of regulatory non-compliance are mediated. Achieving compliance can be seen as a proper response to the communication by the whistleblower, as this achieves the goal of the whistleblower through the regulators enhanced capacity to negotiate compliance by regulated bodies within their network. Further, regulators are operating under severe resource restrictions, and by addressing the risk identified by the whistleblowing disclosure in a co-operative manner the resources of the regulator are conserved, and more action can be taken in the public interest.

In some circumstances more information is necessary in order for the regulator to take action. Regulators may request more information from the whistleblower. This is only possible in circumstances where the person making the disclosure was identifiable. In circumstances where the disclosure was made anonymously, regulators are unable to gain the further information needed to begin or continue an investigation, and no further action is taken. In such a case, the initial speech becomes valueless as, whilst autonomy is supported, regulators cannot utilise the information to achieve enhanced regulatory capacity as the whistleblower is not fully enrolled in the regulatory network.

Disclosures that are received should also be recorded and stored, with the information received periodically analysed. A whistleblowing disclosure may contain information which if considered on its own would be insignificant; however, by combining the information

\footnotetext{
${ }^{67}$ See e.g. Hawkins above n21.
} 
contained in the disclosure with information received from other sources regulatory and enforcement bodies may be able to use the information as intelligence to build a detailed picture of a matter of important public concern. Regulators have greater capacity for analysis as they are repeat players; they constantly seek information about breaches by regulated bodies, and can collate information from a variety of sources to build up a picture of regulatory compliance or non-compliance. However, with the fractured landscape of local authority enforcement, it may not be possible to appropriately record and analyse such information in order to identify national trends. It may be the case that a national regulator, is in a better position to perform such an analysis. In order for this to occur, it will be necessary either to transfer the information to the national regulator, or to ensure that the information is recorded in a common format across local authorities in order that analysis can be carried out on uniform data. From our examination of local authorities it appears that the recording of data is not carried out in a uniform format, as the information disclosed to us was far from uniform. Whilst local authorities do have a method for transferring information to the Food Standards Agency and other authorities where the risk demands action (the Food Alert for Action) or where action has been taken (the Food Alert for Information) the routine transfer of data gathered from whistleblowing disclosures does not appear to be similarly provided for. The management information available for analysis does not therefore appear to be of sufficient quality to enable identification of problematic trends, reducing the capacity of the regulatory network to identify non-compliance.

As well as analysing disclosures for trends, the stored information can provide valuable guidance to a regulator on how it is acting in response to whistleblowing disclosures. An audit of the handling of whistleblowing disclosures should be periodically conducted in 
order to identify the possible improvements in policies and procedures necessary to encourage workers possessing information about regulatory non-compliance to come forward. Information should be recorded in a way that facilitates such analysis.

\section{What happens to disclosures outside the remit of the regulator?}

Disclosures may be shared with other bodies better placed to investigate and ameliorate the risk. This is important in a regulatory state where networks involving multiple regulators, with different remits, function to govern the actions of regulated bodies. The regulatory areas examined involved complex national and multi-national governance networks. The National Audit Office passed 58 disclosures to bodies better placed to deal with them, including to the HSE. The Food Standards Agency transmitted disclosures regarding hygiene and standards matters to local authorities to investigate. Ofwat referred a disclosure relating to selling of particular products to the Financial Services Authority. Monitor shared concerns about the quality of care provided by regulated bodies with the Care Quality Commission.

In some circumstances the disclosure was passed to a regulator who is not a prescribed person. For example, OFWAT referred two disclosures to the DWI. The DWI has regulatory functions in relation to water quality but is not included in the list of prescribed persons. Similarly, Monitor referred two disclosures to the GMC (which was not, at the time, prescribed) for investigation regarding the conduct of doctors.

In some cases the disclosure was passed to more traditional law enforcement authorities. In two cases of fraud disclosed to the NAO, information was passed to the police. The CAA passed information disclosed to them to the police and the Security Service. 
This information sharing exposes a weakness in the prescribed person list adopted under PIDA. If the disclosure was made directly to a person who does not appear on the prescribed persons list the individual making the disclosure would not benefit from second-step protection. This could potentially lead to differential treatment for two co-workers who disclose the same concern to two regulators, on prescribed and one not, where the unprescribed regulator has jurisdiction over the subject matter of the disclosure, and the prescribed regulator passes the concern to the un-prescribed regulator. The worker who discloses to the prescribed regulator may only need to satisfy the tests relating to secondstep disclosures, whilst the worker who discloses to the objectively correct regulator, who is best placed to deal with the concern, has to satisfy the more stringent requirements for a protected third step disclosure. The barriers to enrolment for the second worker are higher than for the first worker, and may function to reduce the informational input into the network.

This paradox is also present where information relates to regulatory non-compliance on an international scale. In such cases the disclosure may need to be shared internationally in order to reach those best placed to ameliorate those risks. ${ }^{68}$ The Civil Aviation Authority, which regulates businesses active in more than one jurisdiction, has shared information received from whistleblowers with counterpart regulators in the USA, Ireland and Tanzania.

Within the local authority sample there was also information sharing with other local authorities. Authorities often passed on concerns to the authority most (geographically) appropriate to deal with them. This usually took place through informational exchange with

\footnotetext{
${ }^{68}$ For a more detailed discussion of such sharing see Richard Hyde and Ashley Savage, 'Cross-Border Concerns: Perils and Possibilities' (2013) 2(3) E-Journal of International and Comparative Labour Studies 116.
} 
a counterpart officer within that authority. There is no standard format for the informal sharing of data, but the communication with a colleague will allow officers to communicate back and forth to obtain the information that is necessary to follow up the risk disclosed by the whistleblower.

\section{How is shared information monitored?}

Where information is shared with a third-party, it may be necessary to monitor how the regulator deals with the concern. This is important for two reasons, first to ensure that the concern is addressed, and therefore that the enhanced regulatory capacity provided by the information is not squandered, and second to ensure that the actions taken by the regulator do not compromise the identity of the whistleblower (potentially preventing future ad hoc enrolment in the regulatory network by whistleblowers). However, post-sharing monitoring is patchy.

Ofwat are typical, with no monitoring following the sharing of disclosures with the HSE or DWI. Monitoring is more often carried out where the sharing regulator is investigating alongside the third-party to whom disclosure is made. Monitor continued to check on the use of whistleblowing disclosures shared with the CQC.

With local authorities some transferred disclosures were monitored, and others were not. There was greater monitoring where the disclosure related to a premises within the local authority area which had been referred to a home or primary authority for action compared to circumstances where an worker in an out of area premises had made a disclosure to the local authority. Where monitoring takes place it tended to be informal communications between officers rather than transfers through formal channels. 
Where disclosure is made to a domestic third-party regulator monitoring is more likely than situations where disclosure is made to a foreign third-party regulator. Where the CAA disclosed information to a domestic third-party regulator they monitored the regulatory action taken. Conversely, where they referred information to a foreign regulator, the outcome was often unknown as that foreign regulator did not give feedback on the steps taken, meaning that the whistleblower who had self-enrolled into the network did not know whether their enrolment had resulted in regulatory action.

\section{5 - Conclusion}

Regulators depend on information; the effective gathering, monitoring, storing and sharing of information is central to their function. However, regulators cannot maintain successful monitoring of every workplace for every hour of the day. This article has identified that there is a strong need for whistleblowing disclosures in regulatory practice. An effective regulatory network needs to enrol whistleblowers to enhance its information gathering capacity. Networks with enrolled whistleblowers are better able to work pro-actively, providing regulators with the capacity to respond before malpractice occurs or a serious lapse in regulatory controls results.

The flexible nature of PIDA has allowed British whistleblowers to become 'possibly the best protected in the world. ${ }^{69}$ However, the detachment between the legal protection for whistleblowers and the regulatory agencies themselves has led to a number of inconsistencies in the way that concerns are handled, which function to discourage whistleblower enrolment. This inconsistency begins with the prescribed persons list under

\footnotetext{
${ }^{69}$ C Camp, Openness and Accountability in the Workplace (1998) 149 NLJ 46.
} 
PIDA. By only prescribing certain regulators a hierarchy of public interest concerns has effectively been established. The likelihood of disclosures to regulators is diminished when they are not given the status of prescribed regulators. Prospective whistleblowers are deterred from raising concerns with such regulatory bodies, creating a barrier to the enrolment of whistleblowers into unprescribed regulators' networks.

The empirical evidence has clearly suggested a need for support for whistleblowers to ensure more are enrolled. A number of changes to regulatory practice can be suggested in order that whistleblowing can achieve its full potential as a key part of regulatory networks. First, regulators should have a policy making clear to potential whistleblowers how disclosure may be made. This should be easily accessible to those who wish to make a disclosure and should be prominently placed on the regulators website, preferably with a direct link from the regulators homepage. Second, consideration should be given to the adoption of a shared definition of whistleblowing, particularly if it is proposed that regulators have a duty to respond to disclosures made by whistleblowers. It was evident from a number of responses that there were differences in understanding as to what whistleblowing means. Diversity of definitions means that data recording will be inconsistent, leading to an unclear picture of whistleblowing disclosures, and potential difficulty in sharing information. Third, national and local policy documents applicable to regulators, for example the Food Law Code, should be redrafted to identify the special features of whistleblowing disclosures, and to emphasise the need to treat such disclosures differently to consumer complaints, particularly when investigating non-compliance. Failure to treat whistleblowers differently can lead to a failure to appropriately protect whistleblowers, and may ultimately discourage whistleblowers from coming forward and 
making a disclosure. Fourth, investigations should not focus on the subject matter of the complaint, but should examine the business (or area of the business) as a whole in order to prevent identification of the whistleblower. This should be enshrined in policy documentation. Fifth, regulators policies should be amended to ensure that they deal with anonymous disclosures. Regulators should be trained to deal with individuals making a disclosure in order to obtain necessary information and to encourage whistleblowers to make the disclosure on a confidential basis. Sixth, information regarding disclosures should be recorded and analysed for both to identify trending regulatory non-compliance and to allow audit of the treatment of whistleblowers in order to identify any weaknesses in policies and procedures. Where data is likely to be transferred between regulators a common data format should be adopted, to allow all the information necessary to be recorded. ${ }^{70}$ Seventh, where information is transferred the progress of the investigation should be monitored and reported to the whistleblowers, as provision of such information should demonstrate to the whistleblower that the concern has been addressed, which may have a positive effect on the willingness of future whistleblowers to enrol in the regulatory network.

Lewis has suggested the introduction of a Public Interest Disclosure Agency. ${ }^{71}$ Whilst such an agency would clearly provide valuable support to whistleblowers, the prevailing political climate (demonstrated in the debates upon adoption of PIDA) appears to be against the creation of a regulatory body to specifically cater to whistleblowing disclosures. Moreover,

\footnotetext{
${ }^{70}$ Consideration could be given to the introduction of a statutory duty to refer disclosures received to regulators with appropriate capacity to deal with them as exists in Australia. This would put on a statutory footing multi-regulator networks where the capacity to gather information from enrolled whistleblowers may be separated from the capacity to respond to the disclosed risk.

${ }^{71}$ David Lewis, The Council of Europe Resolution and Recommendation on the Protection of Whistleblowers (2010) 39(4) Industrial Law Journal 432, 432.
} 
with widespread spending cuts affecting regulators at both national and local level, it is unlikely that such a proposal would be implemented in the immediate future. Therefore, the less radical steps identified above must be taken to improve how regulators deal with information disclosed to them, at least until such time as an overarching system (or agency) is introduced. Without such changes there is a risk that the regulatory value of whistleblowing speech will be impaired. 